\title{
Desarrollo adulto: Transiciones *
}

El concepto de desarrollo adulto nos suena familiar debido al interés persistente que el ser humano ha demostrado en torno a los cambios que se operan en sí mismo con el paso del tiempo. Diferentes culturas han contribuido con varias interpretaciones de la conducta humana y mantenido la atención sobre el tema de toda suerte de pensadores y profesionales. (Erikson, 1978; Colarusso, 1983). Sin embargo, el estudio sistemático y de rigor científico de la vida adulta ha sido muy lento en aparecer. Un cierto determinismo derivado de posiciones psicoanalíticas fomentaba la idea de que una persona a la edad de cinco o quince años ha superado ya las transiciones más críticas de la vida, desde el punto de vista biológico y emocional. A partir de entonces, los únicos acontecimientos de relieve que cabe esperar, estarían relacionados con crisis ambientales o reactivaciones de conflictos creados en el período de la infancia.

El esquema de referencia para esta interpretación responde a la idea de desarrollo como producto de cambios de conducta con características de continuidad en el ciclo vital, fases determinadas, resultados irreversibles, transformación cualitativa-estructural y universalidad (Baltes, 1979). El período de madurez adulta se veía, en consecuencia, como una fase en la cual el organismo adquiere un equilibrio o estabilización entre las disrupciones típicas de la adolescencia y la deteriorización progresiva de la ancianidad.

Esta simplificación conceptual sabemos que procede del énfasis concedido a los estudios biológicos, particularmente los de maduración y personalidad sobre la infancia y la coincidencia de contextos sociales más estables en los que el desarrollo adulto pudo equipararse con el proceso de socialización de la persona a través de un conjunto homogéneo y consistente de tareas y funciones en el ciclo de la vida (Labouvie-Vief, 1982). Sin embargo, bajo la influencia de la investigación psicológica de los últimos veinte años que ha ofre-

* Introducción a este trabajo: «Aspectos clínicos y del desarrollo en la edad adulta». Estudio Agustiniano, Vol. XIX Fasc. III, 1984, 507-512. 
cido estudios en áreas específicas como procesos biológicos normales en el cerebro del adulto (Pribram, 1971), funciones cognitivas y efectos de la socialización (Baltes, 1979), tareas evolutivas (Havighurst, 1972) y aspectos varios de gerontología (Neugarten, 1977), se ha llegado a la conclusión de que los conceptos anteriores de desarrollo adulto no sólo son insuficientes sino inadecuados a las realidades actuales.

$\mathrm{Al}$ presente existen formulaciones parciales, pero bien fundadas sobre características psicológicas de distintos períodos de la vida adulta, diferencias comparativas sobre los sexos, temas y tareas de las transiciones, modos generales de adaptación y superación de conflictos, formas de psicopatología asociadas con estados regresivos en el proceso de desarrollo, etc. Estos trabajos han adoptado metodologías y examinado segmentos de población muy diferentes. Sus contribuciones y limitaciones han sido discutidas suficientemente (Neugarten, 1977; Baltes \& Brim, 1981; Gilligan, 1982; Colarusso, 1983) pudiendo concluir que, aunque no existe aún una teoría global predominante sobre el desarrollo adulto, tenemos sin embargo algunos puntos básicos de convergencia que permiten proceder con cierta seguridad en la labor investigativa y de enseñanza. Entre ellos, la observación común de que los standards de maduración adulta no pueden ser dictados por teorías construidas sobre el desarrollo infantil; que el desarrollo de un adulto no puede definirse en un vacío histórico-cultural puesto que está vinculado intrínsecamente a una corriente de acontecimientos históricos; que el desarrollo humano afecta a todos los períodos de la vida y que el período adulto en particular está caracterizado por un crecimiento dinámico y cambios intrapsíquicos importantes; finalmente, que estos cambios están basados en un esfuerzo de adaptación y se producen en torno a los procesos de transición en los cuales se observa la complejidad de la conducta humana en toda su profundidad y con los matices propios de cada individuo conforme a su historia personal, sexo, edad y contexto existencial.

En torno a esto se puede elaborar un paradigma que propone la noción del desarrollo adulto como un proceso generado por intercambios entre la persona y su ambiente sobre los cuales tienen influencia innumerables factores particularmente biológicos, psicosociales y religiosos. En estos intercambios podemos observar a una persona utilizando una amplia gama de recursos y capacidades con la tendencia no sólo hacia una adaptación básica de sobrevivencia, sino más generalmente orientada hacia la consecución de un nivel satisfactorio de autonomía y expansión de su propio ser.

Como este proceso evolutivo es continuo a través del ciclo vital, por su propia tensión dinámica, facilita la emergencia de situaciones y sucesos que pueden provocar un cambio de perspectiva, ya sea sobre la persona misma o el espacio vital en que se mueve y que consecuentemente requiere también cam- 
bios de conducta. Naturalmente, estos cambios van acompañados de reacciones de stress, formas de conflicto e incluso estados de regresión patológicos, pero simultáneamente ofrecen también la intrínseca posibilidad de crecimiento y consolidación de varios aspectos del ser y su funcionamiento psicosocial.

Las transiciones, por tanto, se refieren a ese tiempo y actividad en que la persona negocia las exigencias de esas situaciones dando sentido a los acontecimientos particulares que ocurren, formulando y modificando su respuesta a los mismos e incorporándoles en su estructura vital como una experiencia global unificada.

La discusión que se ofrece en las secciones siguientes es un análisis de los elementos incluidos en el paradigma que acabamos de enunciar.

\section{Dinámica de la adaptación}

Una premisa fundamental de la ecología humana es la de que la persona existe inmersa de un modo constante en un ambiente, al cual reacciona con las capacidades que tiene a disposición y las tendencias adquiridas (Meyer, 1957). La constante interacción entre persona y ambiente, tanto interno como externo, explica fundamentalmente la aparición de formas y funciones de la conducta (Spitz, 1965). Este dinamismo básico es parte de la condición humana en todas las edades. También puede decirse que todas las formas de conducta son de alguna manera expresiones del esfuerzo de adaptación de la persona a un ambiente. Incluso en las situaciones más triviales la respuesta personal no puede expresarse en términos puramente mecánicos o de rutina. Cada día nos enfrentamos con una serie de problemas que se hacen de la combinación de infinidad de variables. Piense cada uno en ejemplos como éstos: una decisión sobre cuáles van a ser los asuntos a los que se va a dar preferencia en el trabajo de un día; cómo vamos a presentar ideas para una conversación con una persona difícil o antagonista; la elaboración de opciones, estrategias y concesiones que vamos a hacer en la discusión de un proyecto; cómo vamos a mantener estados de satisfacción y serenidad frente a las preocupaciones, trastornos y exigencias ordinarias en las relaciones de familia y amistades. Como resultado, tenemos la impresión de que la vida es un desafío constante y que cada momento requiere una solución nueva y una respuesta adecuada. Muchas de estas negociaciones las consideramos ordinarias, predecibles y la mayoría de las personas de conducen en forma consistente, manteniendo un grado razonable de equilibrio en su ambiente, resolviendo cuestiones y exigencias con un mínimo de esfuerzo y atención por medio de mecanismos y reacciones habituales.

Pero es característico del ser humano el que su esfuerzo de adaptación no se limita simplemente a una supervivencia y mantenimiento de estados de 
equilibrio si no que tiende también hacia aquello que permite su expansión en varias dimensiones. Esta adaptación expansiva tiene manirestaciones complejas que responden a varias urgencias biológicas y psicológicas. Pero quizá la más prominente sea la tendencia hacia la autonomía (Angyal, 1941). Simplemente por el hecho de que la conducta humana esta, en parte al menos, regulada interiormente, presenta de forma consistente una resistencia a los elementos que intervienen desde el exterior. Más aún, simultáneamente tiende a someter esos mismos elementos externos a su propia esfera de influencia. De aquí surge una extensa gama de modos de personalidad con los cuales estamos familiarizados: agresividad, auto-afirmación, curiosidad, estimulación sensorial y cognitiva... para formar un complejo cualificado globalmente como «competencia personal» (White, 1976).

$\mathrm{Y}$ es precisamente en conexión con este esfuerzo hacia la competencia que la actividad inherente a la persona adquiere su más dinámica representación: el poder de iniciativa que proporciona el sentido de ser uno verdadero «agente» en el devenir de la propia existencia. Erikson estableció una de sus famosas polaridades: autonomy vs. dependency sobre esta dinámica y se ha mantenido como esencial al desarrollo adulto, filtrándose en la manifestación de los más importantes temas.

Otra manifestación de adaptación expansiva es la que podríamos llamar asimilación progresiva de valores, entendida como algunos investigadores sugieren, como un movimiento desde lo simple hacia lo complejo, desde orientaciones externas en las cuales el individuo se considera dependiente de la autoridad y juicio ajeno, hacia orientaciones internas en virtud de las cuales asume responsabilidad por las consecuencias de sus propias acciones, desde actitudes absolutistas y dogmáticas hacia una tolerencia por la ambigüedad e incertidumbre que acompañan frecuentemente a las experiencias humanas; desde una tendencia a percibir y enjuiciar a personas ajenas al propio contexto existencial en términos estereotipados, hacia una creciente sensibilidad por las diferencias individuales y mayor capacidad de comprensión por los demás y desde una postura centrada en los propios intereses, hacia otra en la que prevalece el interés común, la conformidad con la opinión mayoritaria e incluso formas maduras de interdependencia con los otros.

El grado de asimilación que surge de estas polaridades evolutivas representa un índice de maduración de la persona que es susceptible de observación y hasta cierto punto también de objetivación. Psicólogos expertos en análisis cuantitativo de características de personalidad han elaborado instrumentos, como el «16 Personality Factor», que revelan la progresión de estos valores en el individuo. Entre otras cosas, cabe notar que su presencia da mayores garantías de desenvolvimiento cuando un adulto se ve confrontado con la prueba de las transiciones. 
$\mathrm{H} z$ sta hace poco las formulaciones teóricas sobre desarrollo adulto consideraban la co.ısecución de un estado general de equilibrio psíquico, en cualquier forma que esto se entendiese, como el objetivo único y final del mismo. De ahí que la ausencia de conflicto, la coherencia de pensamiento, una adecuación sin alteraciones notables entre el organismo y su ambiente y la predominancia de lo que pudiera incluirse en la idea de normalidad, ha sugerido siempre la noción positiva de adaptación satisfactoria y de madurez. Por el contrario, la presencia de cualquier género de conflicto o grado de desajuste ha llevado la connotación de una posible disturbación psicológica. Sin embargo, si bien es cierto que la habilidad del organismo humano para mantener su estabilidad es un componente esencial de su capacidad para sobrevivir, paradójicamente, también lo es su capacidad para crear y tolerar inestabilidad o desequilibrio, y permanecer abierto a nueva información (Labouvie-Vief, 1981). No todas las indicaciones de desorganización, ni siquiera algunas de carácter regresivo, son el resultado directo de una disturbación patológica. A veces, ciertos grados de desintegración pueden indicar la presencia de síntomas transitorios de un movimento evolutivo imprevisto y rápido o nuevos estados de integración.

Varios estudios realizados sobre el concepto de «desintegración positiva» (Laing, 1960; Dabrowski, 1970; Brent, 1978) explican que niveles altos de desarrollo adulto o madurez psicológica no están caracterizados necesariamente por equilibrio, sino que pueden incluir profundos estados de tensión y síntomas como ansiedad, depresión, dudas, ambivalencias, etc., las cuales resultan ser no signos de maladaptación, sino de complejidad estructural psicológica. Para probarlo se han aducido casos de observación longitudinal, por ejemplo, de mujeres que han experimentado serios desajustes hacia la edad de treinta años, con toda la gama de síntomas mencionados, como consecuencia de problemas transicionales relacionados con sus matrimonios, planes de trabajo y carreras, sentido de la propia estima e identidad, etc., y quémás tarde han sido capaces de reorientar sus vidas en toda su complejidad con gran objetividad y eficacia. Observaciones de esta categoría han ayudado a situar el énfasis excesivo sobre la estabilidad en la edad adulta en una perspectiva muy diferente.

Kegan (1982) traza un paralelo entre el proceso de separación e individuación de que se habla en psicoterapia y esta modalidad de «separación del antiguo equilibrio». Solamente los individuos que entran en un activo y creativo envolvimiento con la vida, llegan a experimentar este arduo proceso. Sin embargo, cuando el desequilibrio transitorio se ha superado, se ve la posibilidad de uno nuevo, de una relación con el mundo más articulada y substancial, mejor organizada, que va a diferenciar y reintegrar nuestras percepciones ante- 
riores. Ya no se trata de que el individuo «restaura» su equilibrio perdido, sino que logra un equilibrio de cualidad distinta. Uno no regresa, sino que avanza a través de una nueva integración y dirección.

Más aún, como Cohen (1981) hace notar, quizá el individuo necesita experimentar este desequilibrio psicológico en ciertos períodos de su vida para poder desarrollar ciertas formas de competencia, incrementar su sentido de valer, mejorar sus recursos psicosociales y espirituales, ensayar actitudes maduras, como la capacidad de sintonizar con la experiencia ajena, etc. Por otra parte se ha hecho notar también que la habilidad de concebir y tratar simultáneamente ideas opuestas es un elemento central en el proceso creativo que anima de ordinario las experiencias más valiosas de ciertas personas y las hace excepcionalmente tolerantes para las ambigüedades que experimentan en sí mismas. Y esta capacidad de reconocer, en primer lugar, mensajes conflictivos en su interior y en el mundo ambiental, y después crear una síntesis con un significado y relevancia hacia el futuro, es una señal de maduración indiscutible.

En este sentido pues, el desequilibrio que se produzca es una fuerza positiva y necesaria en el desarrollo adulto. La práctica clínica demuestra (Lowenthal, 1975) que muchas personas en quienes se descubre este núcleo de datos que podríamos cualificar de «contradictorios» resultan ser aquellas que están envueltas profundamente en el mundo de su trabajo y superan con relativa facilidad los conflictos que normalmente hay que esperar de esa forma intensa de vivir, abierta también a la presencia de otros seres humanos.

Varios investigadores han discutido la capacidad de permanecer abierto a nueva información, como otra más de las formas básicas de adaptación. Ha llegado a considerarse incluso como una necesidad desde el punto de vista biopsicológico ya que la idea contraria de «terminación» aplicada a la organización psicológica de un individuo, a cualquier momento de su desarrollo, supone la privación de dinamismo que en realidad está aún en progreso (LabouvieVief, 1980).

Esta capacidad surge como consecuencia de una tensión entre dos fuerzas opuestas, potencialmente enriquecedoras de la persona: el impulso conservativo e innovativo que actúa en torno al mundo asuntivo y el espacio vital de la misma. Estos conceptos se han elaborado sobre la observación de que una persona adulta llega a crear a través de los años, un mundo interior que mantiene creencias e ideas, las interpretaciones del pasado y las expectaciones del futuro, planes y prejuicios, etc. (Parkes, 1971). Todo esto se convierte en una especie de guía privada para nuestras interacciones con el mundo exterior, dando consistencia a una forma única individual de pensamiento que se mantiene firme sobre todo cuando se producen períodos prolongados de relativa estabilidad. En estas circunstancias observamos que las personas desarrollan 
una adherencia profunda a su mundo interior y siguen sin esfuerzo la orientación que en él predomine. Erikson (1980) lo explica diciendo que existe una necesidad primaria hacia la regularidad o ritualización de la experiencia procedente de una «peculiar» visión de la vida.

Paralelo a esto existe lo que Kurt Lewin (1935) llamó el «espacio vital» de una persona, que consiste de todos esos elementos del ambiente que mantienen interacción con el ser humano y en relación al cual la conducta se organiza, incluyendo a otras personas, zonas de familiaridad como la casa, el sitio de trabajo, las posesiones privadas materiales, etc.

El impulso innovativo surge y se nutre de los cambios que se operan constantemente en este espacio vital que ofrece nuevos estímulos, combinaciones sorprendentes de sucesos, y comunicaciones imprevistas procedentes de otros. Algunos de estos cambios se producen gradualmente, son esperados en cierto modo y por tanto requieren poco esfuerzo de adaptación pues afectan el mundo asuntivo sólo superficialmente. Sin embargo, a medida que el impulso innovativo se acentúa, alterando el espacio vital, se produce un signo de discontinuidad. El mundo interior se hace cada vez más extraño y dispar comparado con la nueva información que se presenta, creando una situación de homeostasis precaria. Por ejemplo, las reacciones que siguen a una decisión de divorcio.

Ciertos elementos proporcionados por la nueva experiencia seguramente que contradicen conceptos sostenidos anteriormente, v.gr.: perennidad de una promesa solemnizada religiosamente, sinceridad y realismo del amor humano, etc. forzando el conflicto de revisarlos o descartar la posibilidad de envolverse en la proyectada experiencia. Éste es un momento crucial de las transiciones en el cual juegan un papel importante el factor personal envuelto en el significado que se da al acontecimiento. La persona, en todo caso, se enfrenta con lo desconocido. Importantes elementos afectivos están envueltos también ya que las fuerzas en litigio globalmente integran la idea que uno tiene sobre sí mismo y el mundo externo sostenidas a través de los años y constituyen la base de esa confianza en la existencia propia y la habilidad para sobrevivir. Y es que la simple formulación de una nueva "aventura» en forma de preguntas, reevaluaciones o decisiones, implica sumergirse en el conflicto fundamental relativo a la propia seguridad, una de las más valiosas cualidades de la existencia humana. De ahí la tensión que se observa en todo proceso de transición.

El esfuerzo de adaptación expansiva de una persona utiliza estas formas enunciadas aquí y es importante analizarlas en la modalidad particular que cada individuo pueda presentar. Adaptación, no significa como sabemos por experiencia, ni un triunfo total sobre el ambiente, ni tampoco una rendición incondicional. En general se opera más racionalmente en alguna forma de compromiso aceptable. 


\section{El contexto ambiental}

Si la conducta humana está influenciada por varias formas de regulación interna también lo está por normas y acontecimientos de la realidad externa. La persona existe y se adapta a un contexto histórico-social del cual recibe influencias definitivas en infinidad de aspectos. Este contexto se ha caracterizado en la época actual por rápidos cambios que constituyen un substrato profundo bajo la variabilidad de circunstancias y datos más personales del desarrollo. Alvin Toffler (1970) y Stevens Long (1979) entre otros han ofrecido una descripción incisiva y válida de esta situación concluyendo que nunca anteriormente en la historia se había encontrado el individuo con un contexto ambiental de esta complejidad. Y si por una parte tenemos que reconocer la innegable abundancia de alternativas que acentúan hoy con un signo positivo nuestra condición humana, también tenemos que admitir que esto amenaza nuestras capacidades y límites para confrontarlo y salir adelante en nuestro esfuerzo de adaptación.

La necesidad de tener una referencia conceptual adecuada con vistas no sólo a una comprensión de este contexto sino también a las exigencias prácticas en la aplicación de principios efectivos de intervención psicológica con adultos, obliga a considerar al menos dos dimensiones complementarias: la de los módulos sociales y la de las tareas evolutivas.

Éstas han absorbido un esfuerzo considerable de investigación en sociología, y psicología como prueban los numerosos estudios de (Brim, 1980; Danish, 1980; Kahn, 1980; Fellner, 1983) que analizan en todas sus variables y repercusiones los sucesos asociados con el ciclo vital y con las transiciones.

Los módulos sociales incluyen aquellos acontecimientos que por su generalización, dinamismo e impacto llegan a moldear el ambiente biocultural en el cual se desarrolla el individuo. Por ejemplo, el período inmediato a la guerra mundial para los europeos, 0 «los años sesenta» para la juventud americana. Paralelamente se citan también lo que se ha llamado «dominantes seculares», que abarcan fenómenos como el movimiento feminista o actividades políticas de grupo a nivel regional o internacional que acarrean elecciones, directivas y decisiones de gran alcance para un conjunto humano determinado. Uno piensa en las proporciones que están adquiriendo debates sobre el papel de la mujer en la Iglesia de Estados Unidos; la moralidad del derecho a morir con dignidad; escoger una aborción o mantener una «preferencia sexual» típica de minorias. El impacto y magnitud de estos acontecimientos se debe en gran parte a las reacciones que provocan a varios niveles, su influencia en la adjudicación de recursos en la sociedad, la aparición de sistemas de soporte en las comunidades de menor escala, la creación de funciones, prioridades, ex- 
pectaciones, y sanciones, la posibilidad de crecimiento y al mismo tiempo, la confusión y complicaciones que acompañan.

Otro ejemplo relevante es la movilidad geográfica impuesta por el mercado del trabajo, la planificación a nivel de grandes compañías, la estrategia urbana de expansión orquestada por varios intereses. Esto proporciona amplia oportunidad para contactos breves de carácter superficial, pero hace dramáticamente difícil establecer relaciones humanas profundas y con esa cualidad vital de permanencia que permite experiencias comunes variadas e íntimas y el sentido de lealtad a personas e instituciones. Cambios de ocupación se han hecho más frecuentes y el concepto de «sucesión de carreras» y «trayectorias de trabajo», que explican el fenómeno de individuos en movilidad periódica es un hecho que tiende a generalizarse más y más.

Otra área dentro de esta dimensión de módulos sociales es la que agrupa la extensa gama de «estilos diferentes» que surgen en sistemas de vida colectivos e individuales (Colarusso, 1983), por ejemplo, la familia a la que se ha dedicado en psicoterapia una atención excepcional en los últimos años, observando una evolución rápida en su naturaleza y estructura con la aparición de nuevas formas y variaciones de otras más tradicionales (Levitan \& Belous, 1981). Desde la revolución industrial se ha producido una reducción drástica en el número de hijos por familia, y este pequeño grupo, unido con otros miembros que generalmente viven a distancia, repartidos en un círculo geográfico amplio, se ha convertido en el modelo prevalente. El índice de divorcios ha subido de una forma alarmante y más hijos son cuidados solamente por uno de los padres, generalmente la madre. Este dato se hace todavía más complejo cuando se tiene en cuenta que hoy casi todas las mujeres trabajan en jornadas ordinarias fuera de casa, lo que obliga a enviar a los niños a una edad más temprana y por más tiempo a instituciones sociales atendidas por profesionales. Las normas de conducta sexual con repercusiones en la vida de la familia han cambiado radicalmente. Los miembros de ésta puede decirse que aún tienen mucho en común, sin embargo, viven con frecuencia en mundos diferentes, con diferentes relaciones, intereses y valores.

Otras estructuras familiares nuevas incluyen: la de padres separados, familias modificadas, i.e.: construida después del divorcio por medio de nuevo matrimonio y la de homosexuales. Del mismo modo que conceptualizamos al individuo como un organismo en desarrollo progresivo, así también hay que aceptar la familia. Aunque existen sin duda aspectos favorables en estas formas nuevas también se reconoce que cualquier alteración produce cambios de importancia en la estructura psíquica del individuo por la disrupción de los ritmos y cursos evolutivos, ya que de ordinario requieren que éste se envuelva en una nueva subcultura con sus correspondientes normas y orientaciones de 
conducta. La reorganización intrapsíquica de esta categoría tiene su influencia en el sentido de uno mismo y su estabilidad, imponiendo una reforma de modos de relación con otras personas, con diferentes procesos de gratificación y la necesidad de actuar en diferentes contextos.

No es nuestro propósito analizar otros «estilos diferentes», de gran interés desde el punto de vista clínico, por separado, como el estado soltero, divorcio, segundo matrimonio, variaciones de homosexualidad etc. Pero todos ellos ilustrarían la premisa inicial que hemos establecido sobre la diversidad del proceso evolutivo en los adultos. Más aún, al observar la complejidad inherente a este proceso reconocemos que la orientación y cualidad del progreso que un individuo puede alcanzar en un área determinada, por ejemplo, familiar o sexual no prejuzga el mismo resultado en otras áreas, por ejemplo de amistades, carrera, creatividad, etc. Un caso notable de desarrollo en múltiples direcciones nos lo ofrece Morgan (1980) en su estudio del novelista Somerset Maugham, un bisexual, cuya homosexualidad fue el gran secreto de su vida. Morgan describe la riqueza y complejidad de su personalidad y los diferentes papeles qu asumió en diferentes períodos de su ciclo vital. Maugham fue un niño retraído, estudiante de medicina, bohemio en París, buen autor de teatro, espía en Rusia, homosexual promiscuo, marido engañado, propagandista en la Segunda Guerra Mundial, el novelista más leído de su época y una leyenda dice que intentó desheredar a su hija y en su senilidad adoptar a su secretaria.

El interés que despiertan estilos diferentes como éste es debido en gran parte a que se convierten en «experimentos naturales» en sí mismos para el estudio de los temas y tareas del período adulto. Por otra parte hay que clarificar que la peculiaridad de los estilos diferentes no minimizan la condición universal de los conflictos y temas asociados con varios aspectos del proceso evolutivo y sus resoluciones. La conclusión es que es útil reconocer el hecho de estas variaciones en la existencia humana y que los individuos en particular afectados por ellas son mejor comprendidos como seres humanos en su totalidad que en términos de un aspecto o área de su vida y experiencia.

La segunda dimensión del contexto ambiental está formada por una amplia varièdad de acontecimientos que tienen una relación directa con el individuo y se agrupan bajo el nombre genérico de tareas evolutivas de la vida adulta. Havighurst (1972) en un trabajo importante, que comenzó como un artículo mimeografiado para sus estudiantes en los años 40 y fue impreso sólo hacia 1960 , describe estas tareas como exigencias determinadas por elementos fisiológicos, psicológicos y sociales que una persona tiene que satisfacer con el fin de adquirir un sano y razonable nivel de desarrollo y maduración en la vida. Esos elementos de ordinario coexisten y se interrelacionan a diversos niveles, 
adqueriendo más importancia en unos períodos de la vida que en otros. En general una negociación y solución positiva de cualquiera de esas tareas produce un sentido único de satisfacción, facilitando en el futuro resultados semejantes, del mismo modo que el fracaso, en cualquier forma, trae consigo desconcierto, quizá sanciones sociales y otras dificultades más adelante.

A pesar de los intentos realizados no existe una clasificación de estas tareas que permita indentificarlas con seguridad y de alguna manera relacionarlas con períodos específicos en el ciclo vital. Los esquemas que se han hecho clásicos en los trabajos de Erikson, Piaget y más recientemente Levinson y Havighurst, han suscitado interés y ofrecido gran ayuda para explorar un terreno inicialmente desconocido. Sin embargo, a medida que se ha profundizado en los temas que de ordinario preocupan a la mayoría de los adultos y cuál es el curso de su aparición y resolución, esos esquemas se han ido revisando y complementando en sus líneas más sustanciales, abandonando algunas formulaciones ambiguas o muy rigurosas, que no parecen explicar suficientemente las observaciones consistentes que ahora se tienen provenientes de varias disciplinas.

En este análisis preferimos dar una revisión de esas tareas sin pretensión de rigor descriptivo. De propósito ni siquiera se mencionan edades cronológicas determinadas ya que tanto el número de éstas como sus límites, no gozan al presente de suficiente consensus en psicología clínica.

Estamos acostumbrados a pensar que en esos años que hemos llamado de «adolescencia» la tarea psicológica más importante es la formación de una identidad personal y la de conseguir un acoplamiento razonable entre la sociedad y uno mismo, preparando una especie de «plan de vida» para el futuro. Unos años más tarde, cuando la persona comienza a considerarse como un adulto, los temas que surgen se relacionan con la intimidad sexual, el transformarse uno en figura parental y hacer frente a las exigencias del mundo del trabajo. Las tareas correspondientes orientan hacia la consecución de cierto equilibrio entre los extremos de establecerse o seguir explorando nuevas avenidas; echar algunas raíces, al mismo tiempo que se lucha por conseguir un poco de éxito; salir al encuentro de nuevas obligaciones, especialmente hacia consorte e hijos, dedicando lo mejor de uno mismo a la relación con unos pocos seres humanos a los que uno va a estar unido por largos años, en el futuro, al mismo tiempo que se hace un tanto de progreso en asuntos de individuación, competencia y dominio de la ocupación propia. Las transiciones asociadas con funciones relativas a la familia y el trabajo están creando problemas muy particulares para ambos sexos hoy día. El movimiento feminista ha traído consigo nuevos conflictos en varios aspectos sociales para mujeres que acometen simultáneamente carreras profesionales con el cuidado de hijos menores y 


exigen continuamente cambios en uno mismo y en las formas de adaptación. Con el paso del tiempo el proceso evolutivo no permanece estático en ningún área sino que asimila la riqueza y variedad de modalidades que provee la interacción con el ambiente. Esos temas que hemos mencionado son el núcleo y substancia de conversaciones y confidencias que la gente hace en momentos de iluminación, vivencias profundas y reacción muy personal a los sucesos de la vida y que se comunican en forma de historia verbal o escrita a un amigo o terapista. En realidad no hay una secuencia ordenada para ninguno de ellos, ni en general concuerdan exclusiva o especialmente con ninguna edad. Son asuntos que aparecen una y otra vez en el curso del ciclo vital, se resuelven y vuelven a emerger con nuevas modalidades en diferentes épocas. Fluidez y cambio es la característica innegable de la vida adulta.

En este trabajo coincidimos con Neugarten (1970) en que al estudiar las relaciones entre personalidad, adaptación y transiciones, se debe poner mayor atención sobre los acontecimientos y asuntos que son de más relieve para el individuo mismo, lo que la persona selecciona como importante en su pasado y presente, lo que espera realizar en el futuro, lo que prevee como resultado de sus decisiones, las estrategias que adopta, el significado que da a su tiempo, a la vida y la muerte. Está perspectiva que se cualifica propiamente como «clínica», es fundamental en psicoterapia, mediante la cual el psicólogo establece una comunicación con la persona, haciendo claro el que uno ciertamente entiende algo de la concreta experiencia en la manera en que esa persona misma lo está interpretando y viviendo. La necesidad de subrayar este aspecto tan importante ha sido expuesta ampliamente en psiquiatría a través del trabajo de Heinz Kohut (1984).

Los acontecimientos incluidos bajo estas dos amplias dimensiones señaladas se pueden analizar con relación a varias características de tiempo óptimo, duración, especificidad generacional y repercusión en otros procesos, que se han considerado comunes a todos ellos (Brim, 1980). La perspectiva que de ello se deriva puede tener implicaciones importantes para el planteamiento y delimitación de objetivos en una intervención terapéutica. A este respecto conviene que adelantemos algunas observaciones:

1. El objetivo de esta examinación no es el hacer una proyección sobre la conducta de un individuo como ha sido tradicional en otro tipo de exámenes psicológicos. Tal objetivo, admitimos, no tiene justificación ya que no se pueden hacer predicciones respecto a las variaciones de la conducta humana, particularmente desde nuestra perspectiva del ciclo vital, a pesar de las sofisticación en metodología para el control de variables o categorización de toda clase de acontecimientos que se asocian con las transiciones. La razón primaria es que no se pueden predecir los cambios que pueden efectuarse en el contexto 
social de un individuo ni tampoco las contingencias y especiales circunstancias que pueden surgir en la existencia de una persona, ni siquiera la forma en que su experiencia total como adulto va a ser afectada por aquellos otros individuos que van a jugar un papel íntimo o importante en su vida.

2. Cualquier acontecimiento que se produzca en la historia de una persona no debe prejuzgarse como stress o «crítico», si no es parte efectiva del espacio vital de esa persona y está produciendo un impacto duradero en áreas significativas de su mundo interior asuntivo. En consecuencia, los acontecimientos normales y predecibles en esas dimensiones citadas no constituyen de por sí crisis o traumas. Son más bien «mojones» en el ciclo vital, encrucijadas que traen consigo cambios en el concepto de uno mismo, que provocan tensión y exigen esfuerzo, incluso son precipitantes de nuevas adaptaciones. Pero por sí mismos no son causa de desórdenes psicológicos o desequilibran el sentido de continuidad personal. El factor crucial que los podrían convertir en causas de tal género sería la manera en que el individuo se enfrenta con el proceso de cambio que se produce en su vida, o en otras palabras, el estilo de confrontación que utiliza, de lo cual nos ocupamos más adelante.

3. Se ha observado con acierto, que nuestras instituciones modernas, incluido el sistema educacional no preparan al individuo para una realidad ambiental en la que el factor más crítico es el cambio. El cúmulo de conocimientos y expectaciones cultivados en largos años se declaran insuficientes o desfasados para el tiempo en que el individuo tiene que utilizarlos. Existe también una asunción implícita de que el esfuerzo adaptacional se limita principalmente a los años de formación, lo que hace muy difícil para un gran número de adultos ensayar estilos de adaptación adecuados a su edad y experiencia, puesto que no han hecho uso de oportunidad que se han ofrecido para aprenderlos. Por el contrario, individuos que viven inmersos en su presente actual, pero son capaces de anticipar el futuro y prepararse para ir adelante con él, permaneciendo abiertos al cambio y con la aspiración de continuar creciendo, encuentran menos dificultades en adaptarse a nuevas situaciones y realidades. De la misma manera que otros, careciendo de esa flexibilidad, encuentran que ciertos acontecimientos y ajustamientos toman enseguida proporciones de crisis. Y es en esta línea donde se producen generalmente indicios sintomáticos que se transforman después en factores etiológicos de muchos desórdenes somáticos y psiquiátricos (Dohrenwend, 1979).

\section{Confrontación, stress y resolución personal}

En el paradigma que utilizamos para el análisis de las transiciones hemos subrayado la importancia central del esfuerzo de adaptación para solucionar problemas de interacción con el ambiente. Muchas de estas «negociaciones»

5. Rev. Estudio agustiniano 
se llevan a cabo sin complicaciones, son ordinarias, pero otras provocan una situación difícil que requiere la utilización de diferentes recursos. En la primera sección usamos «adaptación» como un concepto general, y ahora tenemos que referirnos, en particular, a unas estrategias, como se las llama en terapia y que incluyen principalmente: defensa, la cual implica la reacción a una amenaza o ataque de cualquier tipo; dominio, que describe una forma de conducta en la que las frustraciones concomitantes a problemas transicionales se han superado y los esfuerzos de adaptación han dado un resultado positivo; y confrontación que supone a una persona tratando con cambios drásticos o situaciones y experiencias que por su cualidad y circunstancias requieren la utilización de recursos diferentes de los habituales, de ordinario acompañada de stress y síntomas de ansiedad, sentimientos de culpa, vergüenza, desesperación y profundo dolor.

Aunque algunos investigadores tratan de este aspecto concreto de la confrontación acompañada de stress, por separado, como una entidad patológica en sí misma y haciendo énfasis en su efecto negativo, actualmente existe un interés creciente en el papel positivo que el stress puede jugar en el desarrollo humano, ya que es inevitable en el transcurso del ciclo vital y muchas personas no parecen sufrir efectos adversos notables. Esta observación ha provocado algunas cuestiones críticas como éstas: ¿cómo distinguimos un stress que puede proporcionar mayor crecimiento de otro que probablemente se resuelva en una dificultad pasajera y aún de otro que puede crear un trauma, complicarse en forma de crisis o incluso arruinar el equilibrio mental de una persona? ¿Cuál es la razón por la cual algunas personas aceptan fácilmente la perspectiva del cambio y la confrontación de nuevas tareas en el curso de su vida y otras tiemblan ante lo mismo y se aferran a cualquier forma de continuidad? ¿Cómo es así que algunos encuentran de una forma u otra avenidas para solucionar las complejidades que surgen de acontecimientos críticos y otros sucumben psicológicamente ante situaciones de stress muy relativo?

La respuesta global que podría darse haría notar que las probabilidades de que los resultados vayan en una $u$ otra dirección dependen de factores que fundamentalmente se concentran en torno a la persona misma: su historia, sus recursos y limitaciones, la orientación de su mundo cognitivo interior interpretando los acontecimientos de la existencia, el sistemá de soporte social que naturalmente depende de la cualidad de relaciones humanas con que la persona cuenta y las oportunidades que encuentre de actuar y negociar su transición de una forma favorable.

Si nos fijamos en la persona atravesando una transición descubrimos, en primer lugar, una variedad inmensa de modos de confrontación, que demuestran ser útiles para diferentes personas o para la misma persona en diferentes 
circunstancias. Este dato sugiere una cualidad acumulativa inherente a esos modos a través de las experiencias de la vida. Por ejemplo, la resolución adecuada de frustraciones menores en los primeros años conduce, con grandes probabilidades, a un confrontamiento efectivo en la edad adulta. Del mismo, se puede inferir que el confrontamiento durante las transiciones adultas lleva consigo de un modo operante habilidades complejas adquiridas por medio de sucesivas experiencias, incluyendo una transferencia notable de aprendizaje de un acontecimiento a otro y el reinforzamiento de la estima propia que acompaña el hecho de haber salido airoso en situaciones semejantes anteriormente.

Para tener una idea del potencial con que una persona cuenta durante el período de transición es necesario en primer lugar una revisión de su historia, en términos generales. Datos y antecedentes de tipo clínico son esenciales y forman parte de una impresión de conjunto valiosa. A este respecto, Colarusso (1983) afirma que el grado de patología o salud mental que un individuo acarrea sobre su vida adulta tiene una doble influencia sobre su contexto ambiental y sobre la solución que él mismo da a los sucesos transicionales.

Desde un punto de vista práctico diríamos que, un examen de la balanza de déficits y recursos en la persona se hace necesario. Estos conceptos operacionales han sido descritos en un estudio clásico conducido por Lowenthal y sus colaboradores (1975). Por recursos se entienden características como la capacidad de mutualidad, madurez, competencia, optimismo y habilidad para hacer introspección. Déficits, por el contrario, se han considerado sintomas psicológicos que generalmente incluyen ansiedad, hostilidad, insatisfacción con uno mismo. Parece ser que la mayoría de las personas funcionando normalmente presentan una combinación de ambas características que dan como resultado un sentido de satisfacción interna suficiente. Con esto se da a entender que enfocar exclusivamente sobre los «grados de desorden» o «número de síntomas» en·un aislado período de tiempo no hace justicia a la complejidad del ser humano, pues si uno entra en detalle descubre que mucha gente que presenta característica de uno y otro extremo en la polaridad recursos-déficits son precisamente aquellos que están afrontando directamente y a fondo las exigencias del mundo en el que viven. Una perspectiva adecuada tiene que abarcar el curso del ciclo vital para notar la consistencia de algunos de esos datos, trazar su procedencia y efectos en la estructura de la persona y su forma de actuar.

Hay que tener en cuenta también factores psicológicos personales de cierta clase como por ejemplo antecedentes socioculturales, edad, sexo, desarrollo intelectual y emocional y resolución de experiencias transicionales anteriores. En este área se puede advertir con frecuencia que el individuo acarrea por sí 
mismo la ocurrencia de sucesos cuyas demandas y complicaciones de stress sobrepasan su preparación. Billing \& Moos (1982) han notado que se ha dado demasiada importancia a los sucesos transicionales per se, asumiendo que ocurren quizá espontáneamente, pero ignorando el hecho de que ciertas personas tienen la propensión a experimentar repetidamente gran número de sucesos negativos debido a problemas emocionales latentes o disfunciones de tipo físico o circunstancias sociales adversas que se perpetúan sin alteración en su ciclo vital.

De igual modo, Dohrenwend (1979) y otros han observado que una serie de sucesos que tradicionalmente han formado parte de listas para el examen del impacto de sucesos transicionales aislados, como la de Holmes \& Rahe, pueden ser considerados no sólo como causas sino mejor aún quizá como manifestaciones de dificultades psicológicas pre-existentes en el individuo. Por ejemplo dificultades sexuales, divorcios, inadaptabilidad al trabajo, discusiones crónicas con personas en relación íntima, etc. Todo esto puede ser considerado a veces más como consecuencia que como causa de psicopatología. Por eso quizá se les ha cualificado como datos «contingentes» para indicar que con frecuencia el individuo y su historia personal antecedente juegan un papel activo en su aparición. Este punto de vista, consiguientemente, obliga a pensar que el nivel de funcionamiento psicológico de un individuo puede influenciar el tipo de experiencias transicionales y ser responsable, en parte, por la asociación consistente que se halla entre sucesos de carácter negativo como los citados arriba y varias disfunciones patológicas. En otras palabras, hay grandes probabilidades de que los sucesos que se consideran generalmente como negativos sean una experiencia común entre individuos que funcionan con dificultades desde el punto de vista psicológico (Felner, 1983).

Una persona que experimenta el impacto de una transición se ve obligada a desenvolverse simultáneamente con los requerimientos siguientes: contener el stress dentro de límites tolerables, atender a los detalles del problema particular de que se trata, mantener la propia estima estrechamente vinculada al sentido de identidad y preservar las relaciones interpersonales en su sistema social de soporte (Hamburg, 1982).

La conducta de un individuo en estos momentos se orienta básicamente a convertir lo que podríamos llamar nuevo o inesperado en algo más familiar, haciendo el ámbito existencial más predecible. Esto facilita de por sí una respuesta adaptacional más efectiva ya sea somática, cognitiva, emocional, interpersonal u organizativa. Es frecuente también el que la persona utilice estrategias múltiples que reflejan no sólo su historia evolutiva sino también las diferentes circunstancias que pueden ocurrir en cada transición así como las influencias culturales que favorecen unas estrategias sobre otras en diferentes momentos. 
La regulación de stress emocional es crucial y Caplan (1981) la explica diciendo que el individuo reacciona en primer lugar contra el impacto de un nivel de stress que amenace su salud física y mental. Aunque no todas las transiciones llevan consigo este impacto, la conducta del individuo es muy similar a la que se observa en otros que atraviesan situaciones más drásticas, las que anteriormente se cualificaban como «crisis». Caplan y su grupo en Harvard ha hecho notar a este respecto la disminución característica, en estas circunstancias, de las capacidades cognitivas de un individuo y sus habilidades para resolver problemas. En términos de aplicación terapéutica diríamos que esta disminución de facultades es proporcional a la intensidad del impacto emocional y la consiguiente disforia sufrida. Fenómenos concomitantes incluyen disturbación de la atención, de capacidad discriminativa y asimilación de información, de accesibilidad de recuerdos que acoplan asociaciones interpretativas derivadas del pasado con lo que está ocurriendo en el presente, de juicios y racionalizaciones, de capacidad para planear y evaluar las reacciones provocadas en el ambiente.

Se puede decir por tanto que se produce una alteración en el proceso normalmente ordenado de las funciones instrumentales de la estructura psicológica de la persona. $\mathrm{Y}$ esto ocurre precisamente al tiempo en que este funcionamiento es sumamente valioso para confrontar el problema que la transición está presentando.

Además de estos fenómenos relacionados con el funcionamiento psicológico bajo el impacto de condiciones principalmente externas, una persona bajo stress manifiesta también características de una deterioración del concepto de uno mismo. Normalmente pierde contacto con memorias positivas que ayudan a mantener y valorarse en lo que es, independientemente de lo que está pasando. La «difusión de identidad» que Erikson describe como típica de la adolescencia se podría comparar con los síntomas que se observan en esta parte del proceso de confrontación.

Là estrategia más valiosa en este momento de la transición ha sido descrita por Lazarus (1981) y Hamburg (1982) entre otros, como la habilidad de crear cuanto antes un «núcleo interno de control». La idea es la de controlar los componentes somáticos y subjetivos de las emociones que acompañan el stress, de tal manera que no sobrepasen las capacidades reactivas de contención de la persona misma, afectando negativamente o destruyendo su moral y su funcionamiento en el ámbito social. Quizá la reacción típica a este estado de conmoción es lo que mejor cualifica el grado de ajustamiento de una persona y donde vemos en operación los mecanismos que invariablemente conducen a resultados de normalización o patológicos. El ejemplo más generalizado que podemos aducir en este sentido lo proporcionan muchas personas recu- 
rriendo a varias adiciones, la violencia dirigida contra otros en forma de abuso verbal o físico, tentativas de suicidio o un ataque psicótico. Los que tienen ya una historia de utilización de estas reacciones como respuesta inmediata al stress, ofrecen siempre un riesgo de reincidencia en sus desórdenes psicológicos. Por el contrario, personas que se han ejercitado en un confrontamiento inicial utilizando estrategias efectivas que incluyen cierta disciplina mental y física, creencias religiosas, motivaciones éticas, dedicación a causas humanitarias u otros valores (Thurnher, 1975), logran movilizarse rápidamente pasando a otras fases del proceso y en condiciones de atender a otras exigencias del mismo.

La posibilidad de crear este «núcleo» está en relación directa, como es de suponer, a los recursos con que la persona cuenta y que hemos mencionado antes. Si no existen o sólo en un grado mínimo, la intervención terapéutica tiene que ayudar a formarlo. Ésta es la tarea fundamental de «reconstrucción» psíquica que se ofrece en una institución psiquiátrica. Recientemente Berglas \& Levendusky (1985), Harvard Medical School, han introducido un tratamiento en consonancia con lo que estamos discutiendo aquí y cuya estrategia principal está dirigida a desarrollar capacidades cognitivas de confrontación y repertorios de control interno. Las personas a quienes se aplica se las provee de procedimientos basados no solamente en el análisis de su sintomatología (o del problema en cuestión), sino también en un análisis diferencial de su estilo personal. En este programa se hace énfasis en dos aspectos críticos: a) clarificar al paciente que se le está enseñando a confrontar no sucesos específicos de stress, sino sus reacciones iniciales a los mismos; b) se repite constantemente el mensaje de que la función del terapista es educativa y de orientación, haciendo ver al mismo tiempo que es el paciente el que realmente aplica el esfuerzo y la voluntad necesaria para controlar la situación. También, y como consecuencia lógica, cualquier medicación prescrita en este programa se introduce no como una solución de la disfunción psíquica sino como una ayuda para minimizar el efecto de la misma en el funcionamiento general de la persona, de tal forma que ésta puede demostrar cuanto antes reacciones de mayor cualidad adaptacional.

En segundo lugar, se ha dicho que la persona tiene que atender a los detalles del problema concreto. Las estrategias de valor a este respecto se derivan principalmente de una característica de personalidad que implica resistencia 0 el poder interno de recuperarse de reacciones desintegrativas ante un stress y de retorno rápido a un funcionamiento apropiado (Murphy, 1974). Varios dinamismos sutiles parecen envueltos en esto que requieren, entre otras cosas: a) reforzar la esperanza humana con algunas expectaciones hacia el futuro y la decisión de utilizar cualquier soporte social accesible, junto con mecanismos 
de defensa, que aunque primitivos, puedan dar resultado; b) movilizar recursos disponibles de modo que, aunque uno tenga que reconocerse debilitado por el impacto de stress, se manifieste sin embargo un gesto de superación; c) flexibilidad en el esfuerzo que se hace y en el afecto que se experimenta, lo cual se trasluce en la habilidad de ver y sentir de un modo diferente como resultado de una nueva reordenación del mundo interior asuntivo (Felner, 1983), de una modificación de la situación original, de una re-definición de funciones personales o un progreso modesto en la capacidad de reajuste; d) y finalmente, habilidad para responder a elementos sustitutivos como son nuevos objetos de interés y oportunidades para canalizar reacciones de ansiedad y agresividad en una dirección más constructiva.

Al mencionar arriba la utilización de defensas no podemos dejar de comentar que aunque el modo de pensamiento tradicional en psicología nos ha insistido siempre que el mejor estilo de confrontación es realístico, basando en ello un predicamento mayor de ajustamiento normal, también sabemos que los seres normales tienden a sacrificar su lealtad a una realidad social de consensus bajo el efecto de presiones o stress. Ver, expresar o entender las cosas como son "en realidad», objetivamente, es deseable, pero no siempre posible inmediatamente. Generalmente las personas necesitan dar un rodeo, principalmente porque al mismo tiempo que tienen que mantener una aceptable relación con el mundo exterior, también tienen que mantener un mínimum de «lógica intrasubjetiva» o de coherencia consigo mismos, para sobrevivir psicológicamente (Haan, 1981; Lazarus, 1981). El término que se usa para identificar este rodeo estratégico es el de «equilibración». Entonces estas equilibraciones dominadas por elementos non-logicos, intuitivos y afectivos ocurren cuando la situación como tal no admite reacciones realísticas, o lógicas y en consecuencia no da lugar a un «buen funcionamiento», al menos temporalmente. La persona se ve obligada a negar, fragmentar aspectos intolerables de la realidad interna y externa cuando llega a la conclusión de que no puede tomar un curso de acción inmediata más efectivo para superar las dificultades.

En estas condiciones, la sobrevivencia psicológica impone por ejemplo el que uno a veces tolere un alto nivel de ambigüedad, otras el permitirse cierta forma de «ilusión deceptiva», distorsión de la verdad, intelectualización (para adquirir cierta distancia afectiva del objeto de amenaza) o desviación de una idea destructiva persistente. Todo esto nos hace sentir mejor, pues aunque cualificamos estos mecanismos de primitivos, son no obstante efectivos desde el punto de vista de adaptación. $Y$ aunque las condiciones en que la persona se encuentra no cambian, sin embargo, la influencia beneficiosa temporal se produce y ayuda a la recuperación momentáneamente, y hasta que se puedan emplear defensas más realistas. 
La resistencia activa por tanto, en esta forma, se convierte en un dinamismo psicofisiológico que ayuda a restaurar energías en el período más inmediato al impacto de stress en la transición. El terapista, en el momento conveniente, puede ayudar a utilizar estrategias más detalladas como las que se ofrecen en paradigmas para resolución de problemas y que son aplicables a individuos, grupos y familias (Reiss \& Olivieri, 1980). Pero todas ellas deben acomodarse al caso particular.

Tercero, se ha observado que existe una relación inversa profunda entre la experiencia de stress en una transición y el grado de satisfacción que se deriva de la estima propia, cuyo mantenimiento es siempre crucial (Levinson, 1980). Esta característica de personalidad es el resultado, en términos psicodinámicos, de una coordinación entre el yo-ideal (la forma en que uno se ve a sí mismo en el mejor estilo) y el yo-real (tal como la persona se ve en la situación actual): dos términos que tienen sus raíces profundas en fantasías e introspecciones, pero también en circunstancias evolutivas como las que se producen en las transiciones, en las cuales la persona se confronta con realidades nuevas. La diferencia que se advierte entre ambas se internaliza de muchas maneras, causando stress, pero especialmente:

a) Cuando se producen sentimientos de impotencia o inadecuación con referencia al ambiente. Por ejemplo, ciertas organizaciones no parecen tomar en cuenta los efectos devastadores que siguen como resultado de cambiar a uno arbitrariamente de su puesto o sitio de trabajo, de reducir su status, de privarlo de ciertas aspiraciones importantes y otras intervenciones semejantes. Frecuentemente el individuo responde con una experiencia de sentirse psicológicamente desamparado y solo. Otras circunstancias muy comunes incluyen aquellas en la que la organización no aprecia la calidad o resonancia del trabajo ejecutado a través de los años con un gesto de evaluación a nivel personal y directo, sino al contrario, dando la impresión de que lo que en realidad cuenta es la entidad como tal, su progreso, prestigio y otros conceptos abstractos impersonales que se suelen aplicar: También, y como consecuencia de los cambios rápidos que se producen actualmente en todos los sectores, muchas personas se convierten en víctimas de la doble influencia ejercida por la edad y el desfasamiento en el dominio de su ocupación regular. Cuando una persona se da cuenta de que «no está al día», se siente más fácilmente amenazada. Además, a medida que se avanza en edad, se tiende a sentirse desplazado progresivamente, provocando el que uno se concentre en intereses idiosincráticos o haciéndose cada vez más dependiente de estructuras protectoras, todo lo cual se confabula para hacer a esa persona aún más vulnerable a los efectos de las decisiones que la institución tome sobre ella.

b) Cuando los valores o standards personales sufren extorsión como re- 
sultado de manipulaciones externas que la persona no ha podido predecir o controlar, lo cual precipita en sentimientos de culpabilidad, confusión e ira. Esto puede ocurrir en una variedad de circunstancias, por ejemplo, cuando uno se ve forzado a asumir responsabilidades que no están de acuerdo con su orientación vital o defender principios, decisiones, formas de actuar impuestas por individuos en autoridad que no coinciden necesariamente con la que uno mismo considera adecuada. La coincidencia de que la persona en cuestión depende de las estructuras que originan estas situaciones con un impacto en su bienestar general, nivel de moral o suficiencia económica, puede provocar una tensión de proporciones intolerables. En todos estos casos la imagen ideal de la persona sufre un ataque brutal. Depresiones y una especie de paralización afectiva son consecuencias comunes. Con frecuencia también se forma un núcleo de ira reprimida que después se expresa verbalmente o en escritos contra individuos e instituciones con los cuales la persona ha trabajado y servido quizá por muchos años, con lealtad y eficiencia.

c) Cuando el individuo tiene la impresión de que su vida no hace ningún progreso hacia objetivos substanciales como son: más autonomía, oportunidades y estímulo para su crecimiento. Esta aspiración profundamente humana puede ser fácilmente inhibida por fuerzas sociales y culturales que de ordinario van asociadas con maniobras en la distribución del poder, evaluaciones sobre el individuo, su trabajo y su historia, frecuentemente hechas por quienes quizá no tengan un conocimiento adecuado y directo del mismo. Para mantener su propia estima, el individuo necesita una confirmación de que su posición en la estructura social de la comunidad corresponde razonablemente bien a la imagen de su «yo mejor». De lo contrario, existe la posibilidad de que en un momento dado surjan síntomas de disturbación física y psicológica. Los ejemplos que podríamos aducir a este respecto presentan más complicaciones aun cuando no existen canales adecuados de comunicación y diálogo. Ciertos procesos críticos de adaptación se ven así totalmente bloqueados, provocando en consecuencia que la persona se haga más defensiva, rígida, y experimente mayor stress.

Finalmente, la urgencia de preservar las relaciones interpersonales, nos sitúa en el centro de acción del proceso adaptacional pues los seres humanos no pueden adaptarse al ambiente por sí solos. Son extremadamente dependientes de otros seres y se ven forzados a hacer esfuerzos colectivos para tener éxito. Esta tendencia parece activa en las relaciones humanas de cierta importancia en todos los períodos del ciclo vital, aunque las razones para la formación de lazos afectivos y la manera en que éstos se expresan en diferentes edades y contextos son muy variadas. Estos lazos y la satisfacción que proporcionan no solamente sitúan a la persona adecuadamente en su contexto ambien- 
tal, sino que también la integran como una entidad única, acentuando su experiencia de «una vida con sentido», promoviendo su crecimiento, protegiéndolo contra los efectos del tiempo, y aumentando sus probabilidades de sobrevivir con un grado razonable de felicidad y satisfacción, incluso con perspectivas de acrecentar sus potencialidades. En suma, la comunidad humana se constituye en un mecanismo esencial adaptativo para la persona en su relación con el ambiente (Hawley, 1950).

Ésta es la base para considerar como esenciales los sistemas de soporte social que se encuentran en la vida de una persona y que se han definido como transacciones interpersonales que incluyen elementos afectivos, de afirmación y ayuda (Kahn, 1980, Caplan, 1981). Un soporte social puede confirmar y reforzar, en momentos críticos, defensas de negación y distanciamiento y validar de varias maneras la idea de que las proporciones de su problema no son tan grandes o la amenaza tan inminente, de que en su momento será capaz de atacarlo adecuadamente y superarlo, incluso que las consecuencias de la experiencia no van a ser tan serias. También puede ayudar al individuo a desviar su atención hacia otros asuntos para crear una zona de distracción relajante. Frecuentemente, una de las primeras influencias positivas del soporte social consiste en reducir la sensibilidad emocional de la persona en transición, alimentando generosamente sus necesidades de dependencia, que por el momento están frustradas, por medio de una gradual absorción de su hostilidad, reparando la falta de optimismo y disipando afectos profundos de vergüenza, humillación y abandono.

Los tipos de relaciones interpersonales que son objeto de constante estudio son: relaciones íntimas, familia y grupos de amistades o núcleos comunitarios. En cuanto a la primera, Fiske \& Weiss (1977) mantienen que estas clases de relaciones caracterizadas por una especial confianza, soporte, mutuo entendimiento e intercambio de experiencias, son un importante recurso durante las transiciones. De hecho, muchos individuos encuentran la motivación para vivir una existencia autónoma y satisfactoria solamente en una relación íntima. Incluso cuando éstas son alteradas por razones de distancia, enfermedad o conflicto, aún continúan siendo un recurso primordial para la persona a través del ciclo vital. El simple hecho de haber sido capaz de establecer y mantener una de ellas proporciona una base suficientemente sólida para la superación de las dificultades. En la práctica clínica, es considerado como un factor crítico para una prognosis favorable en ciertas categorías de desórdenes psicológicos.

El soporte de carácter emocional proveniente de miembros de la familia ha sido considerado tradicionalmente de una importancia decisiva. Algunos estudios recientes (Caplan, 1976) incorporan nuevas ideas sobre los cambios 
que han hecho un impacto en este ámbito y que hemos mencionado anteriormente. En general, sigue siendo válida la más incisiva característica de estas relaciones de que actúan como un factor protectivo contra la posibilidad de desórdenes psicológicos principalmente por incluir una asociación directa con el individuo por medio de un trato «único y personalizado». Esas otras personas hablan su mismo lenguaje experiencial, pueden decirle lo que se espera de él, ilustrándole en la forma de responder adecuadamente. Ejercer también una suerte de supervisión y evaluación de sus acciones, añadiendo intervenciones correctivas y de soporte cuando son necesarias. Sobre todo son sensitivas a sus necesidades personales, las cuales se consideran dignas de respeto y satisfacción. El soporte ofrecido puede ser continuo o intermitente según las circunstancias, pero en todo caso activan varios elementos, especialmente, ayudando a la persona a movilizar recursos psicológicos y dominar sus complicaciones emocionales, facilitando la negociación de aspectos de la transición y proveyendo ayudas muy específicas como pueden ser dinero, trabajo, orientaciones para mejorar sus probabilidades de salir adelante con la situación.

Es importante el que anotemos el hecho de que el nivel de soporte social que un individuo puede lograr depende no solamente de estructuras ambientales y de la intervención de otros, sino también de sus propias habilidades y preferencias, cuando se trata de atraer interés o atención en su favor. Al individuo en transición, se le debe considerar un agente activo de su situación organizando, modificando y utilizando los soportes sociales.

Estudios correlacionales han investigado la posibilidad de que el efecto positivo de soporte social se debe en gran parte a la competencia del individuo mismo. Algunas personas, evidentemente, están en cierto modo mejor «inmunizadas» contra los efectos adversos de stress y son también quizá las que tienen más desarrolladas las relaciones interpersonales, como resultado de su mayor competencia social (Heller, 1983). La pregunta entonces es: ¿cuáles son las habilidades que proporcionan un acceso más directo y mantenimiento de soportes sociales? Procidano (1981) que ha revisado datos relacionados con esta pregunta sugiere un número amplio de características, entre ellas: socialidad o extraversión, seguridad personal, tolerancia de intimidad, poca ansiedad en situaciones sociales, habilidad conversacional y para asumir funciones varias (i.e.: de entender el punto de vista ajeno y colocarse en la situación de otros) y la habilidad para resolver problemas sociales (i.e.: capacidad para crear alternativas a problemas de cierta dificultad desde el punto de vista social).

Aunque la competencia para desenvolverse en cualquiera de estas áreas parece depender de variables predisposiciones y educación a una edad temprana, existe también evidencia de que adultos en diferentes niveles de funciona- 
miento normal, incluso los que sufren de deficiencias psicológicas severas, pueden adquirirla con cierto esfuerzo de aprendizaje (Bond \& Rosen, 1980).

Las observaciones hechas hasta aquí ofrecen una visión del potencial inherente a los sistemas de soporte social. Ni que decir tiene que esto puede ser utilizado para abuso y coerción, o si por el contrario no se ofrece, puede dejar a la persona expuesta a los riesgos de aislamiento y abandono haciéndola muy vulnerable a otras posibles contingencias deletéreas (Hamburg, 1982).

El papel que juegan dentro del sistema de soportes sociales diversas clases de grupos está siendo objeto de renovada atención por parte de psicólogos y sociólogos y se centra en organizaciones de trabajo, instituciones religiosas, grupos políticos, grupos especiales de soporte, agencias de ayuda y otros servicios comunitarios. Aunque cada uno de éstos puede desarrollar una función de soporte peculiar a sus estructuras y objetivos, existe un movimiento, como hemos notado en la introducción a este trabajo, que extiende una acción preventiva por medio de programas orientados a ofrecer la ayuda adecuada para tiempos de transición o dificultades similares, a través de un entrenamiento específico por parte de profesionales. La idea ha partido del planteamiento propuesto por Caplan y su grupo en Harvard que consideran esta modalidad como más afín con la forma en que se puede hacer una intervención efectiva en nuestra sociedad moderna. En el fondo existe la convicción de que los profesionales ofreciendo ayuda deben aprender a utilizar el potencial inherente en las relaciones interpersonales, incluyendo a individuos particulares bien dotados y encontrar formas de trabajar con ellos de tal forma que estos «paraprofesionales» puedan utilizar adecuada y constantemente ese potencial (Caplan, 1976; Danish, 1980).

\section{Intervención durante las transiciones}

Estudios recientes en el área de evolución adulta indican que los seres humanos crecen y cambian de forma notable con o sin ayuda profesional. Esto se ha hecho claro en el trabajo de Erikson (1963), Levinson (1978), Neugarten (1981), Vaillant (1977) y otros. Este último, por ejemplo, en su estudio de hombres entre los 15 y 40 años, concluye que el crecimiento toma la forma de una espiral compuesta de fases alternativas de disturbación e integración, en la cual la resolución pasitiva de una de ellas, predispone a un resultado favorable también en la siguiente. Vaillant ve a la gente creciendo hacia un mayor envolvimiento social y utilización de defensas más maduras, independientemente de si se ha requerido una intervención terapéutica.

¿Cuáles son las implicaciones prácticas de estos datos cuando se trata de facilitar la superación y resolución adecuada de las transiciones?

Fundamentalmente la siguiente: si se considera al individuo evolucionan- 
do, sujeto a múltiples influencias y con capacidad de cambio a través de todo el ciclo vital, entonces el encuentro de una persona y el terapista, es simplemente una más de esas influencias, requerida en un momento específico, generalmente porque el esfuerzo adaptacional en busca de alternativas o recursos ha fallado y al presente no se pueden confrontar el cúmulo de exigencias o el impacto del stress emocional (Bennett, 1984). Por otra parte, la persona puede percibir la necesidad de cambiar algún aspecto en sí misma que considera como una contribución al problema presente o que la hace más vulnerable con respecto a algún tema particular.

Esta forma de pensar es frecuentemente asociada con el suceso más inmediato al comienzo de la transición y con la formulación de objetivos y planes por el mismo individuo. Como quiera que éstos son susceptibles de variaciones en diferentes períodos, la presentación o historia que una persona hace de su transición suele estar vinculada al momento en el cual se requiere ayuda. $\mathrm{Al}$ principio, por tanto, es importante clarificar un cuadro de referencia evolutivo concreto y el problema o asunto más saliente en el mismo, dando el relieve necesario a la experiencia que la persona está viviendo, en términos de un movimiento hacia una mayor madurez y salud psicológica total, de forma que los obstáculos más arduos puedan ser removidos:

Este cuadro de referencia es la base de una intervención compatible con los enunciados generales del desarrollo del adulto y requiere específicamente: a) atención al contexto de la transición, b) análisis del problema, c) establecimiento de una relación terapéutica.

En cuanto al primer elemento, la mayor parte de las intervenciones que se aplican bajo el nombre genérico de psicoterapia tratan a la persona fuera de su ambiente normal. El riesgo que se corre, como consecuencia, en estas circunstancias es el de un tratamiento que parece ignorar el hecho de que esa persona no vive en un vacío existencial, sino en un contexto ambiental específico. A la hora de formular los objetivos de la intervención es esencial una clarificación sobre particularidades del contexto de esa persona: funciones que está desarrollando, relaciones humanas, stress de tipo social, recursos interiores y otros elementos que forman parte de lo que Levinson llama «la estructura de la vida». Más aún, la idea misma de contexto incluye otra dimensión importante: la que acompasa las aspiraciones, ambiciones legítimas e ideales de esa persona, en otras palabras, lo que trata de ser y de realizar. Esta dimensión no ha sido sino raramente explorada en intervenciones terapéuticas que siguen el modelo psicoanalítico tradicional, pero tiene una repercusión de grandes alcances ya que responde a la formulación de objetivos fundamentales y al mantenimiento de la propia estima que, como citamos anteriormente, es central en el proceso de superación de la transición y de alguna manera está coloreada de 
características típicas, del período concreto en el que la persona se encuentra con respecto a su ciclo vital.

Por ejemplo, al comienzo de la vida adulta el esfuerzo más serio y de hondas repercusiones que una persona tiene que hacer es el de separarse de su familia de origen. Con frecuencia esto inicia una transición importante con dinámica psicológica de separación, dependencia vs. independencia, requiriendo la confrontación y dominio de reacciones afectivas complicadas y equilibrando las fluctuaciones de estima propia que suelen acompañar. Preocupaciones de carreras que de ordinario han afectado más al hombre hacia los treinta años - pero comienza a ser común experiencia para las mujeres también - constituyen un test crítico para ciertos aspectos de la personalidad como la capacidad de asertividad y de competencia. Sin embargo, y como contraste, unos años después el proceso evolutivo normal presenta diferentes objetivos. Al intentar establecer una relación íntima con otra persona, el adulto tiene que adoptar actitudes casi opuestas y aprender a ser apropiadamente abierto, confiado y comunicativo. El énfasis ahora está en saber renunciar a un cierto grado de autonomía y tolerar la proximidad de otro ser humano en una nueva asociación de interdependencia.

Más tarde, en cualquier punto de esa edad madura a que nos hemos referido, la persona experimenta que la vida impone cierta modulación de ambiciones, la reconciliación de objetivos muy individuales con la necesidad de guiar a la siguiente generación o de servir de puente entre la generación más joven y la de los propios padres; la reflexión sobre la propia mortalidad con su variedad sutil de preguntas y preocupaciones. La forzada reducción de opciones y oportunidades de actuación en la vida; la aceptación del hecho de que uno es una entidad limitada en perfección haciendo jornada en un mundo igualmente imperfecto, junto con la necesidad de continuar siendo accesible a otras personas, estableciendo nuevos lazos de amistad, a pesar de la realización aguda de la contingencia pervasiva de unos y otros. Todo ello forma el núcleo de un contexto con una relevancia transcendental para el análisis de una transición (Budman et alia, 1981).

Paradigmas de intervención y tratamiento que no hacen énfasis en este contexto corren el peligro de confiar excesivamente en el punto de vista del psicólogo sobre los seres humanos y su interpretación de lo que éstos buscan esencialmente, aprecian o temen en la vida y lo que es sano o perjudicial para ellos. $\mathrm{O}$ también puede caerse, como tanto se ha criticado y con razón, en una acentuación exagerada de síntomas psicopatológicos, ya sea en 'forma de estados reactivos (psicosis) o de módulos de conducta, medidos y analizados en consonancia con una vaga idea de normalidad.

Segundo, una investigación sucinta de la experiencia clínica demuestra 
que muchos problemas que se presentan en la edad adulta envuelven una $u$ otra de estas complicaciones:

1. Falta de habilidad para negociar una separación con el pasado o dificultades en aceptar y asimilar las pérdidas y contingencias sufridas en la realización de funciones anteriores, junto con la resignación envuelta en el período de separación.

2. Incapacidad de llegar a una decisión sobre el camino a escoger o la dirección a tomar; y la vacilación en asumir una nueva función o continuar cierto plan de acción.

3. Dificultades en proyectar sobre la realidad una decisión por carecer de comprensión adecuada sobre las implicaciones envueltas en el cambio, falta de información sobre las expectaciones de uno mismo y otros sobre la nueva función o falta de preparación para llevarla a cabo o enfrentarse con otras inesperadas complicaciones.

4. Dificultad en sortear el período de ajustamiento hasta que los cambios se han estabilizado y el proceso transicional puede considerarse terminado. Esto podría ser consecuencia de una falta de recursos para llevar a cabo los cambios requeridos.

Dentro de este esquema habría que incluir también varios tipos de problemas que surgen de decisiones inadecuadas que se han tomado anteriormente $o$ como consecuencia de las reacciones adversas de otros a los cambios que uno ha hecho o está en el proceso de hacer. Y con más razón aún, las crisis agudas situacionales que se presentan como una exacerbación de los cambios transicionales o una complicación que surge en este tiempo concreto.

Como quiera que no solamente individuos sino también familias pueden envolverse en muchos aspectos diferentes de estas dificultades señaladas, resulta casi imposible predecir cuáles son las situaciones que van a constituirse en el problema saliente de la transición. Ciertamente que todos esos factores anotados ya antes: características de personalidad, problemas sin resolver que se acarrean de otras transiciones o períodos evolutivos, la cualidad de los soportes sociales y recursos ambientales, los valores culturales o religiosos y el grado de interés de la comunidad en la resolución de los problemas ocasionados por transiciones en la vida de sus miembros, etc. van a tener una importancia definitiva a este respecto. La distinción entre meras «dificultades» que generalmente la persona por sí misma puede resolver y «problemas» que implican la falta de habilidad para resolver la situación sin alguna forma de ayuda profesional, es muy imprecisa y como consecuencia, la línea divisoria entre ambas, un asunto fuera de control.

Finalmente, el establecimiento de una relación terapéutica, nos sitúa frente al aspecto más sensitivo en la resolución de una transición. En el caso 
de que se vea la necesidad de recurrir a una ayuda profesional para superar el problema, es importante anotar la diferencia entre orientaciones terapéuticas dirigidas al tratamiento de un desorden psicológico y una intervención aplicada a las transiciones adultas. En este último caso, que nos concierne aquí directamente, en general se puede decir que la relación entre la persona en consulta y el profesional toma una nueva dirección. La autoridad de éste y su competencia se usa más enérgicamente y en respuesta a la buena disposición para confiar y relacionar que se observa de ordinario en el individuo, particularmente en el período inicial, más crítico, cuando se siente desorientado, ansioso y sin ayuda. Una transferencia limitada pero positiva, permite un grado notable de envolvimiento en situaciones caracterizadas por stress intenso. A distintas etapas del proceso la relación va estableciéndose sobre un denominador firme y constante, con distintas cualidades.

Comu micra que la mayor parte de las dificultades que surgen en el período adulw. k alguna manera están asociadas con relaciones humanas deficientes, parece evidente que uno de los ingredientes más importantes en la nueva relación terapéutica debe tener una cualidad de calor, interés y autenticidad que confirme la idea de que la persona es aceptada como es, con todas sus limitaciones y errores.

Además, dado que los adultos que experimentan una transición están negociando un proceso normal de crecimiento, este tipo de «transferencia» puede llevar consigo implicaciones terapéuticas y educacionales más allá de la naturaleza y asunto de la intervención. Y aunque la intensidad de la comunicación cambie a medida que la persona en consulta atraviese diferentes fases de la transición el establecimiento y continuación de este «compromiso» recíproco cuyo objeto es facilitar el crecimiento del consultante, debe mantenerse hasta que la transición se ha superado claramente y la persona se encauza de nuevo en la vida con su independencia, fortalecida con nuevas relaciones, y una visión normalizada del futuro. 


\section{REFERENCIAS}

1. Angyal, A., Foundations for a science of personality. New York; The Commonwealth Fund, 1941.

2. Baltes, P.B. Life-span developmental psychology: some converging observations on history and theory. In Life-span development and behavior, New York: Academic Press, 2, 1979, 255-279.

3. Baltes, P.B. \& Brim, O.G. (Eds.), Life-span development and behavior. New York: Academic Press, 3, 1981, 253-286.

4. Bennett, M.J. Brief psychotherapy and adult development. Psychotherapy, 21, 1984, 171-177.

5. Billings, A.C. \& Moos, R.H. Stressful life events and symptoms: a longitudinal model, Health Psychology, 1, 1982, 99-117.

6. Bond, L.A. \& Rosen, J.C. (Eds.), Competence and coping during adulthood. Hanover, N.H: University Press of New England, 1980.

7. Brent, S.B. Individual specialization, collective adaptation and rate of environmental change. Human Development, 21, 1978, 21-33.

8. Brim, O.G. \& Kagan, J. (Eds.), Constancy and change in human development. Cambridge, MA: Harvard University Press, 1980.

9. Budman, S., Bennett, M. \& Wisneski, M.J. An adult developmental model of short term group psychotherapy. In Budman, S. (Ed.), Forms of brief psychotherapy. New York; Guilford, 1981. 305-343.

10. Caplan, G. \& Killilea. M. (Eds.), Support systems and mutual help. Multidisciplinary explorations. New York: Grune \& Stratton, 1976.

11. Caplan, G. Mastery of stress: psychosocial aspects. American Journal of Psychiatry, 4, 1981, 413-420.

12. Cohen, F. Research notes on stress. Psychiatric Clinics of North America, 2, 1981, 261-273.

13. Colarusso, C.A. and Nemiroff, R.A. Adult development. A new dimension in psychodynamic theory and practice. New York: Plenum Press, 1983.

14. Dabrowski, K., Mental growth through positive disintegration. London: Gryf, 1970.

15. Danish, S.J., Smyer, M.A. \& Nowak, C.A. Developmental intervention: enhancing life event processes. In Baltes, P. \& Brim, O.G. (Eds.), Life-span development and behavior. New York: Academic Press, 1980, 339-366.

16. Dohrenwend, B.S. Life events and psychopathology; some issues of theory and method. In J.E. Barret (Ed.), Stress and mental disorder. New York: Raven Press, 1979, 40-85.

17. Erikson, E.H. (Ed.) Adulthood. New York: W.W. Norton \& Co., 1978.

18. Erikson, E.H. Themes of adulthood in the Freud-Jung correspondence. In Smelser, N. \& Erikson, E.H. (Eds.), Themes of Work and love in adulthood. Cambridge, MA: Harvard University Press, 1980, 105-126.

19. Felner, R.D., Farber, S.S. \& Primavera, J. Transitions and stressful life events: a model for primary prevention. In Felner, R., Jason, L., Moritsugu, J. \& Farber, S. Preventive psychology: theory, research and practice. New York: Pergamon Press, 1983, 199-215.

20. Fiske, M. \& Weiss, L. Intimacy and crises in adulthood. In Schlossberg, N.K. \& Entine, A.D. (Eds.). Counseling adults. Monterey, CA: Brooks/Cole, 1977, 80117. 
21. Gilligan, C. In a different voice. Cambridge, MA: Harvard University Press, 1982.

22. Haan, $\mathrm{N}$. Adolescents and young adults as producers of their own development. In Lerner, R.M. \& Busch-Rossnagel, N.A. Individuals as producers of their own development. New York: Academic Press, 1981, 155-182.

23. Hamburg, D.A., Elliot, G.R., Paron, D.L. (Eds.), Health and Behavior. Frontiers of research in the behavioral sciences. Washington, D.C.: National Academy Press, 1982.

24. Havighurst, R.J. Developmental tasks and education. New York; David McKay Co, 1972.

25. Hawley, A. Human ecology. New York; Ronald Press, 1950.

26. Heller, K., \& Swindle, R.W. Social networks, perceived social support and coping with stress. In Felner, R., Jason, L., Montsugu, J \& Ferber, S. Preventive psychology. New York; Pergamon Press, 1983, 87-103.

27. Kahn, R.L. \& Antonucci, T.C. Convoys over the life course: attachment, roles and social support. In Baltes, P.B. \& Brim, O.G. (Eds.), Life-span development and behavior. New York: Academic Press, 1980, 51-67.

28. Kegan, R. The evolving self. Problem and process in human development. Cambridge, MA; Harvard University Press and London, England, 1982.

29. Kohut, Heinz. How does analysis cure? Contributions to the psychology of the self. Edited by Arnold Golberg and Paul Stepansky. Chicago: University of Chicago Press, 1984.

30. Labouvie-Vief, G. Discontinuities in development from childhood to adulthood. A cognitive-developmental view. Human Development, 23, 1980, 447-455.

31. Labouvie-Vief, G. Proactive and reactive aspects of constructivism: growth and aging in life-span perspective. In Lerner, R., \& Busch-Rossnagel, N. (Eds.), Individuals as producers of their own development. New York: Academic Press, 1981, 70-95.

32. Laing, R.D. The divided self, New York: Pantheon, 1960.

33. Lazarus, R.S. The stress and coping paradigm. In Eisdorfer, C., Cohen, D., Kleinman, A, et. al: Models for clinical psychopathology. New York: Spectrum Publications, 1981, 46-65.

34. Levinson, D.J., Darrow, C.N., Klein, E.B., Levinson, M.H., \& McKee, B. The seasons of a man's life. New York: Alfred Knopf, 1978.

35. Levinson, $\mathrm{H}$. An overview of stress and satisfaction: the contract with the self. In Bond, L.A. \& Rosen, J.C. (Eds.), Competence and coping during adulthood. Hanover, N.H. University Press of New England, 1980, 225-239.

36. Levitan, S.A., \& Belous, R.S. What's happening to the American family? Baltimore, MD: Johns Hopkins University Press, 1981.

37. Lewin, K. A dynamic theory of personality. New York: McGraw, 1935.

38. Lowenthal, M.F., Thurnher, M.F. \& Chiriboga, D. (Eds.), Four stages of life: $A$ comparative study of women and men facing transitions. San Francisco: JosseyBass, 1975.

39. Meyer, A. Psychobiology: A science of Man. Comp. \& ed. E.E. Winters \& A.M. Browers. Springfield, III: Thomas, 1957.

40. Morgan, T. Maugham. New York: Simon \& Schuster, 1980.

41. Neugarten, B.L. Middle age and aging: A reader in-social psychology. Chicago: University of Chicago Press, 1968. 
42. Neugarten, B.L. Adaptation and the life cycle. Journal of Geriatric Psychiatry, 4, 1970, 71-87.

43. Neugarten, B.L. Personality and aging. In Birren, J.E. \& Schaie, K.W. The psychology of aging. New York: Van Nostrand Reinhold, 1977.

44. Parkes, C.M. Psychosocial transitions: A field for study. Social Science and Medicine, 5, 1971, 101-115.

45. Pribram, K. Languages of the brain: Experimental paradoxes and principles in neuropsychology. Englewood Cliffs, N.J: Prentice Hall, 1971.

46. Procidano, M.E. An analysis of social competence in schizotypic, subclinically depressed and subclinically psychopathic individuals. Umpublished doctoral dissertation. Indiana University, 1981.

47. Reiss, D., \& Olivieri, M.E. Family paradigm and family coping: A proposal for linking the family's intrinsic adaptive capacities to its response to stress. Family Relations, 29, 1980, 431-444.

48. Spitz, R. The first year of life. New York. International Universities Press, 1965.

49. Stevens-Long, J. Adult Life. Palo Alto, CA: Mayfield, 1979.

50. Thurnher, M. Continuities and discontinuities in value orientations. In Lowenthal, M.F. et al. Four stages of life. San Francisco: Jossey-Bass, 1975.

51. Toffler, A. Future shock. New York: Random House, 1970.

52. White, R.W. Strategies of adaptation: An attempt at systematic description. In Moos, R.H. (Ed.), Human adaptation: Coping with life crises. Lexington, MA: Heath, 1976, 17-32.

ANDRÉS NIÑO, OSA

New York, 1985 